\title{
Pu-Erh Tea Extract Induces the Degradation of FET Family Proteins Involved in the Pathogenesis of Amyotrophic Lateral Sclerosis
}

\author{
Yang Yu, ${ }^{1,2,3}$ Shuhei Hayashi, ${ }^{2,4}$ Xianbin Cai, ${ }^{2}$ Chongye Fang, ${ }^{2,5}$ \\ Wei Shi, ${ }^{1}$ Hiroko Tsutsui, ${ }^{2,4}$ and Jun Sheng ${ }^{5}$ \\ ${ }^{1}$ Key Laboratory for Molecular Enzymology and Engineering, The Ministry of Education, Jilin University, Changchun 130012, China \\ ${ }^{2}$ Department of Pu-Erh Tea and Medical Science, Hyogo College of Medicine, 1-1 Mukogawa-cho, Nishinomiya, Hyogo 663-8501, Japan \\ ${ }^{3}$ State Key Laboratory of Phytochemistry and Plant Resources in West China, Kunming Institute of Botany, \\ Chinese Academy of Sciences, Kunming 650201, China \\ ${ }^{4}$ Department of Microbiology, Hyogo College of Medicine, 1-1 Mukogawa-cho, Nishinomiya, Hyogo 663-8501, Japan \\ ${ }^{5}$ Key Laboratory of Pu-Erh Tea Science, The Ministry of Education, Yunnan Agricultural University, Kunming 650201, China
}

Correspondence should be addressed to Shuhei Hayashi; zoup1130@hyo-med.ac.jp and Jun Sheng; shengj@ynau.edu.cn

Received 7 November 2013; Revised 1 March 2014; Accepted 10 March 2014; Published 7 April 2014

Academic Editor: Tibor Hortobagyi

Copyright (C) 2014 Yang Yu et al. This is an open access article distributed under the Creative Commons Attribution License, which permits unrestricted use, distribution, and reproduction in any medium, provided the original work is properly cited.

FET family proteins consist of fused in sarcoma/translocated in liposarcoma (FUS/TLS), Ewing's sarcoma (EWS), and TATAbinding protein-associated factor 15 (TAF15). Mutations in the copper/zinc superoxide dismutase (SOD1), TAR DNA-binding protein 43 (TDP-43), and FET family proteins are associated with the development of amyotrophic lateral sclerosis (ALS), a fatal neurodegenerative disease. There is currently no cure for this disease and few effective treatments are available. Epidemiological studies indicate that the consumption of tea is associated with a reduced risk of developing neurodegenerative diseases. The results of this study revealed that components of a pu-erh tea extract (PTE) interacted with FET family proteins but not with TDP-43 or SOD1. PTE induced the degradation of FET family proteins but had no effects on TDP-43 or SOD1. The most frequently occurring ALS-linked FUS/TLS mutant protein, R521C FUS/TLS, was also degraded in the presence of PTE. Furthermore, ammonium chloride, a lysosome inhibitor, but not lactacystin, a proteasome inhibitor, reduced the degradation of FUS/TLS protein by PTE. PTE significantly reduced the incorporation of R521C FUS/TLS into stress granules under stress conditions. These findings suggest that PTE may have beneficial health effects, including preventing the onset of FET family protein-associated neurodegenerative diseases and delaying the progression of ALS by inhibiting the cytoplasmic aggregation of FET family proteins.

\section{Introduction}

Amyotrophic lateral sclerosis (ALS) is one of the major motor neuron diseases. It is a rapidly progressive neurological disorder that involves the degeneration of motor neurons, leading to paralysis and death [1]. In most cases, the disease develops in subjects aged between 40 and 60 years. Currently, there is no effective treatment available for preventing the inexorable neurodegeneration that eventually results in death within 1-5 years after the symptoms emerge.

Most cases of ALS are sporadic, but approximately 10\% are familial. Several mutant genes have been identified in patients with familial ALS. The first mutations identified were in the SOD1 gene on chromosome 21 [2]. Recently, TDP-43 and FET family proteins have also been identified as being involved in the development of both ALS and frontotemporal lobar degeneration (FTLD) [3-9]. FET family proteins and TDP-43 are RNA-binding proteins that are structurally and functionally similar $[10,11]$, which have been associated with multiple nuclear and cytoplasmic steps of RNA processing [12]. The accumulation of FUS/TLS in the cytoplasm of the nervous systems of patients with FUS/TLS mutations disrupts its normal nuclear localization [13]. Most of the FUS/TLS mutations cluster in the C-terminus of the FUS/TLS 
protein, while R521C FUS/TLS is the most common mutation of FUS/TLS-associated ALS [14]. Although the mechanisms responsible for the aggregation of TDP-43 and FET family proteins are currently unknown, the increased stability of the mutant or wild-type TDP-43 protein has the potential for causing toxicity through abnormal proteostasis and RNA dysregulation [15]. A histone acetyltransferase inhibitor, referred to as anacardic acid, was reported to rescue the abnormal ALS motor neuron phenotype through the inhibition of TDP43 protein expression [16]. Transgenic mice that overexpress human FUS/TLS have limb paralysis and death occurs by 12 weeks in homozygous mice [17]. The overexpression of human mutant FUS/TLS (R521C substitution) leads to progressive paralysis that resembles ALS in transgenic rats [18].

$\mathrm{Pu}$-erh tea is mainly produced in the Yunnan Province of China and is widely consumed in southeastern Asia owing to its unique flavor and potential health benefits. $\mathrm{Pu}$-erh tea, unlike green tea, is a type of fermented tea and includes microbial metabolites. A number of in vitro and animal studies have demonstrated that pu-erh tea has antioxidant [19] and antiobesity properties [20]. Pu-erh tea also has strong anticancer protective effects [21] and can ameliorate diabetic nephropathy [22]. Several compounds are produced during the postfermentation of pu-erh tea. These compounds are produced from the degradation of proteins and carbohydrates and the oxidation of polyphenols by the enzymatic action of microorganisms [23]. The chemical characteristics and bioactivities of pu-erh tea remain unclear.

The identification of proteins that bind to components of pu-erh tea extract (PTE) will aid in our understanding of the molecular and biochemical mechanisms that underlie its effects. Moreover, the identification of the target proteins that associate with PTE will be useful in the development of new strategies with the objective of understanding its biological functions of pu-erh tea. In this study, we used PTE Sepharose $6 \mathrm{~B}$ beads and MALDI-TOF MS to purify and identify proteins associated with PTE from cell lysates. The results of this study revealed that PTE interacts with FET family proteins and induces the degradation of FET family proteins. The findings suggest that pu-erh tea is a potential natural source of protection against neurodegenerative diseases that are associated with FET family proteins.

\section{Materials and Methods}

2.1. Reagents and Antibodies. PTE, green tea extract (GTE), and black tea extract (BTE) were kindly supplied by the China Academy of Pu-Erh Tea Research $[21,22]$. These extracts were dissolved in distilled water and adjusted to $\mathrm{pH} 7.4$ with $1 \mathrm{M}$ $\mathrm{NaOH}$. Ammonium chloride $\left(\mathrm{NH}_{4} \mathrm{Cl}\right)$, a lysosomal inhibitor, was purchased from Wako Pure Chemical Industries (Osaka, Japan). Lactacystin (Calbiochem, Bad Soden, Germany) was dissolved in dimethyl sulfoxide (DMSO). Sodium arsenite solution was purchased from EMD Millipore (Darmstadt, Germany). Anti-FUS/TLS, anti-LDLR (low density lipoprotein receptor), anti-TDP-43, anti-V5, anti- $\beta$-actin, and horseradish peroxidase-conjugated secondary antibody were purchased from Santa Cruz Biotechnology (Santa Cruz, CA), Abnova (Taipei City, Taiwan), Cell Signaling Technology (Beverley, MA), Invitrogen (Carlsbad, CA), Sigma (St. Louis, MO), and Thermo Scientific (Waltham, MA), respectively. Anti-EWS and anti-TAF15 were purchased from Cell Signaling Technology (Beverley, MA). The SOD1 antibody was a kind gift from Dr. Noriko Fujiwara.

2.2. Cell Culture. The human neuroblastoma cell line (SK$\mathrm{N}-\mathrm{SH}$ ) was purchased from the European Collection of Cell Culture (Salisbury, UK). SK-N-SH cells and HEK 293T cells were cultured in DMEM supplemented with $10 \%$ fetal bovine serum. The human acute $\mathrm{T}$ lymphoblastic leukemia cell line (MOLT-3) was grown in RPMI-1640 medium supplemented with $10 \%$ fetal bovine serum.

2.3. Preparation of Tea Extract Sepharose 6B Beads. Epoxyactivated Sepharose 6B beads were purchased from GE Healthcare Bio-Sciences Corporation (Little Chalfont, UK). The equal amounts of PTE, GTE, and BTE were prepared according to the same procedure. The Sepharose $6 \mathrm{~B}$ beads that served as a control were prepared according to the same procedure.

2.4. Purification of PTE-Associated Protein. Briefly, $1 \times 10^{7}$ MOLT-3 cells were lysed in buffer (1\% Triton X-100, $10 \mathrm{mM}$ Tris, $150 \mathrm{mM} \mathrm{NaCl}, \mathrm{pH}$ 7.6). A four-step procedure for the purification of the PTE-associated proteins was performed. In the first step, the lysate was added to Sepharose $6 \mathrm{~B}$ beads and incubated with gentle rocking overnight at $4^{\circ} \mathrm{C}$. The samples were then centrifuged and the supernatant was collected. In the second step, the supernatant was added to the GTE Sepharose 6B beads and incubated with gentle rocking overnight at $4^{\circ} \mathrm{C}$, and the supernatant was collected by centrifugation. In the third step, the second-step supernatant was added to BTE Sepharose $6 \mathrm{~B}$ beads, which were then incubated overnight at $4^{\circ} \mathrm{C}$, and the supernatant was isolated by centrifugation. In the final step, the third-step supernatant was added to PTE Sepharose 6B beads and the supernatant was incubated overnight at $4^{\circ} \mathrm{C}$. The PTE Sepharose $6 \mathrm{~B}$ beads were then washed five times with lysis buffer. The proteins that were bound to the beads were analyzed on SDS-PAGE. Cell lysates without any treatment served as the controls. The gels were stained with Coomassie brilliant blue (Nacalai, Kyoto, Japan).

2.5. MALDI-TOF MS Analysis. The protein band of interest was excised from the gel and analyzed by matrix-assisted laser desorption ionization-time-of-flight mass spectrometry (MALDI-TOF MS) (Microflex LRF 20, Bruker Daltonik $\mathrm{GmbH}$, Bremen, Germany). The peptide masses were entered into Mascot (http://www.matrixscience.com/), and the NCBI database was searched to identify the protein.

2.6. Pull-Down Assay. Cells lysates were obtained with lysis buffer (1\% Triton X-100, $10 \mathrm{mM}$ Tris, $150 \mathrm{mM} \mathrm{NaCl}, \mathrm{pH}$ 7.6) and incubated with PTE Sepharose 6B beads (or Sepharose 
$6 \mathrm{~B}$ beads as the control). After incubation with gentle rocking overnight at $4^{\circ} \mathrm{C}$, the beads were washed five times with lysis buffer, and proteins that were bound to the beads were analyzed by Western blot.

2.7. Western Blot. Whole cell extracts were prepared with RIPA buffer (1\% NP-40, 0.5\% sodium deoxycholate, $1 \mathrm{mM}$ EDTA, 50 mM Tris-Cl [pH 7.4], $150 \mathrm{mM} \mathrm{NaCl}, 25 \mathrm{mM} \mathrm{NaF}$, $1 \mathrm{mM}$ DTT, $1 \mathrm{mM} \mathrm{Na} \mathrm{VO}_{4}$, and $1 \mathrm{mM}$ phenylmethylsulfonyl fluoride [PMSF]). Protein concentrations were determined with a BCA Protein Assay Kit (Pierce, Rockford, IL). The proteins were separated by SDS-PAGE, transferred to Immun-Blot PVDF membranes (Bio-Rad, USA) and blocked with $5 \%$ skimmed milk. The processed membranes were then incubated overnight at $4^{\circ} \mathrm{C}$ with primary antibodies. Horseradish peroxidase-conjugated secondary antibodies were then added and the membranes were incubated for $1 \mathrm{~h}$ at room temperature. The signal was detected with SuperSignal Dura Substrate (Pierce, Rockford, IL).

2.8. Cell Viability. Cell viability was quantified using Trypan blue stain $(0.4 \%)$ and a Countess Automated Cell Counter (Invitrogen, Carlsbad, CA).

2.9. Plasmid Construction. The open reading frames of human FUS/TLS, FUS/TLS R521C mutant and LDLR were amplified from a human cDNA library and cloned into pcDNA3.1/V5/His-TOPO (Invitrogen, Carlsbad, CA) and then verified by sequencing. Primer sequences are shown in Table 1.

2.10. Transfection. A total of $1 \times 10^{6} \mathrm{SK}-\mathrm{N}-\mathrm{SH}$ cells were transfected with $2 \mu \mathrm{g}$ of FUS/TLS, FUS/TLS R521C mutant and LDLR plasmids using the Amaxa-Nucleofector-System (Lonza, Allendale, NJ, USA) according to the manufacturer's instructions. At $48 \mathrm{~h}$ after transfection, cells were treated with or without PTE $(200 \mu \mathrm{g} / \mathrm{mL})$ for an additional $24 \mathrm{~h}$ and the cells were then collected for Western blot analysis. Transfections of HEK 293T cells were performed using XtremeGENE HP (Roche, Mannheim, Germany) following the manufacturer's protocol.

2.11. Establishment of SK-N-SH Cell Lines Expressing R521C FUS/TLS. To generate R521C FUS/TLS-expressing cells, SK$\mathrm{N}-\mathrm{SH}$ cells were transfected by the Amaxa-NucleofectorSystem. Transfected cells were cultured for 4-6 weeks in G418 $(0.6 \mathrm{mg} / \mathrm{mL})$. G418-resistant cells were screened for R521C FUS/TLS expression by Western blot.

2.12. RT-PCR. The expression of FUS/TLS mRNA was analyzed by RT-PCR. The total RNA of SK-N-SH cells was extracted using the RNeasy Mini Kit (Qiagen, Hilden, Germany). Cell cDNA was prepared with a PrimeScript RTPCR Kit (Takara, Dalian, China) using random primers. Quantitative RT-PCR was performed with Taqman Universal PCR Master Mix (Applied Biosystems, Foster City, CA) in an ABI 7500 Real Time PCR System (Applied Biosystems, Foster City, CA). The FUS/TLS and $18 \mathrm{~S}$ rRNA primer/probe sets
TABle 1: Primer sequences.

\begin{tabular}{|c|c|}
\hline Primer & Sequence $\left(5^{\prime}\right.$ to $\left.3^{\prime}\right)$ \\
\hline $\begin{array}{l}\text { FUS/TLS WT } \\
\text { forward }\end{array}$ & ACCATGGCCTCAAACGATTATACCCAAC \\
\hline $\begin{array}{l}\text { FUS/TLS WT } \\
\text { reverse }\end{array}$ & ATACGGCCTCTCCCTGCGATCCTGTCTG \\
\hline $\begin{array}{l}\text { FUS/TLS } \\
\text { R521C forward }\end{array}$ & ACCATGGCCTCAAACGATTATACCCAAC \\
\hline $\begin{array}{l}\text { FUS/TLS } \\
\text { R521C reverse }\end{array}$ & ATACGGCCTCTCCCTGCAATCCTG \\
\hline$L D L R$ forward & ACCATGGGGCCCTGGGGCTGGAAATTG \\
\hline$L D L R$ reverse & CGCCACGTCATCCTCCAGACTGAC \\
\hline $\begin{array}{l}G A D P H \\
\text { forward }\end{array}$ & GAAGGTGAAGGTCGGAGTC \\
\hline $\begin{array}{l}G A D P H \\
\text { reverse }\end{array}$ & GAAGATGGTGATGGGATTTC \\
\hline
\end{tabular}

(Applied Biosystems, Foster City, CA) were purchased from commercial sources. The relative quantification of FUS/TLS mRNA was analyzed using the manufacturer's software with $18 \mathrm{~S}$ rRNA as the reference gene. To perform semiquantitative RT-PCR, the PCR products were electrophoresed on an agarose gel. Primer sequences are shown in Table 1.

2.13. Immunofluorescence Analysis. SK-N-SH cells stably expressing FUS/TLS R521C were seeded onto 4-well LabTek II CC chamber slides (Nalge NUNC International, Rochester, NY). The cells were treated with or without PTE $(200 \mu \mathrm{g} / \mathrm{mL})$ for $24 \mathrm{~h}$, washed once with PBS, and fixed with $4 \%$ paraformaldehyde in PBS (5 min at RT). Following washing with PBS, the cells were permeabilized with $0.5 \%$ Triton X-100 in PBS for 10 min and blocked with PBS containing 1\% BSA (Sigma-Aldrich, St. Louis, USA) with $0.05 \%$ Tween 20 for $30 \mathrm{~min}$. The cells were incubated overnight at $4^{\circ} \mathrm{C}$ with mouse anti-V5 $(1: 1000)$ antibody, washed with PBS/0.05\% Tween 20 (PBST), and incubated with biotinylated anti-mouse IgG antibody $(1: 200$; Vector Laboratories, Burlingame, CA) and Alexa Fluor 594-strepavidin conjugate (1:100; Invitrogen, Carlsbad, CA) for $30 \mathrm{~min}$. After washing with PBST, the coverslips were mounted on slides with Prolong Gold antifade reagent containing $4^{\prime}, 6^{\prime}$-diamidino2-phenylindole (DAPI) (Invitrogen, Carlsbad, CA). The cells were observed using a confocal Zeiss LSM 510 microscope (Carl Zeiss Ltd., Hertfordshire, UK).

2.14. Statistical Analysis. All experiments were repeated at least three times. Data are expressed as the mean \pm SEM. The statistical differences were evaluated using one-way analysis of variance (ANOVA) and Student's $t$-test. $P$ values of less than 0.05 were considered significant. 
TABLE 2: Identification of the PTE binding protein based on peptide fragments produced by MAILDI-TOF MS.

\begin{tabular}{|c|c|c|c|c|c|}
\hline Peptide & Start-end & Observed & Mr (expt.) & $\mathrm{Mr}$ (calc.) & Delta $M$ \\
\hline K.KTGQPMINLYTDR.E & $90-102$ & 1536.7841 & 1535.7768 & 1535.7766 & 0.0002 \\
\hline K.KTGQPMINLYTDR.E + oxidation (M) & $90-102$ & 1552.7707 & 1551.7635 & 1551.7715 & -0.0080 \\
\hline K.TGQPMINLYTDR.E & $90-102$ & 1408.7088 & 1407.7015 & 1407.6816 & 0.0199 \\
\hline K.TGQPMINLYTDRETGK.L & 91-106 & 1823.8919 & 1822.8847 & 1822.8883 & -0.0037 \\
\hline K.LKGEATVSFDDPPSAK.A & $107-122$ & 1661.8517 & 1660.8444 & 1660.8308 & 0.0136 \\
\hline K.AAIDWFDGKEFSGNPIK.V & $123-139$ & 1894.9324 & 1893.9251 & 1893.9261 & -0.0010 \\
\hline K.CPNPTCENMNFSWP.N & $202-215$ & 1698.6680 & 1697.6608 & 1697.6749 & -0.0141 \\
\hline K.APKPDGPGGGPGGSHMGGNYGDDR.R & $223-246$ & 2252.9478 & 2251.9406 & 2251.9665 & -0.0259 \\
\hline NCBI database & & GI:62087384 & & & \\
\hline
\end{tabular}

\section{Results}

3.1. Purification and Identification of PTE-Associated Protein. In order to isolate the PTE-associated protein, Sepharose $6 \mathrm{~B}$ beads, GTE Sepharose 6B beads, BTE Sepharose 6B beads, and PTE Sepharose 6B beads were prepared. Proteins obtained from the MOLT-3 cells were loaded onto the four types of Sepharose $6 \mathrm{~B}$ beads and mixed overnight at $4^{\circ} \mathrm{C}$, and the proteins that bound to the four types of Sepharose $6 \mathrm{~B}$ beads were then analyzed by SDS-PAGE. Two protein bands were detected $(70 \mathrm{kDa}$ and $130 \mathrm{kDa})$ that were bound to the PTE Sepharose 6B beads but not to GTE or BTE Sepharose $6 \mathrm{~B}$ beads (Figure 1(a)). To separate the protein bands from each other, a four-step procedure for the purification of the PTE-associated proteins was performed. MOLT-3 cell lysates were sequentially loaded onto Sepharose 6B beads, GTE Sepharose 6B beads, BTE Sepharose 6B beads, followed by PTE Sepharose $6 \mathrm{~B}$ beads. The proteins that bound to the beads were subjected to SDS-PAGE. The $70 \mathrm{kDa}$ and $130 \mathrm{kDa}$ protein bands were observed, which suggested that the $70 \mathrm{kDa}$ and $130 \mathrm{kDa}$ proteins were specific for associating with PTE (Figure $1(\mathrm{~b})$ ). To identify the $70 \mathrm{kDa}$ protein and $130 \mathrm{kDa}$, the protein bands were excised from the gel and analyzed by MALDI-TOF MS. These mass spectrums were compared with protein databases, and the $70 \mathrm{KDa}$ and $130 \mathrm{KDa}$ proteins were identified as FUS/TLS (Table 2) and Heterogeneous nuclear ribonucleoprotein A1 (hnRNP A1) (data not shown), respectively.

3.2. Confirmation of FET Family Proteins as PTE Associated Proteins. Further evidence for the interaction between FUS/TLS protein and PTE was obtained by a pull-down assay using total proteins obtained from SK-N-SH cells, a human neuroblastoma cell line, Sepharose $6 \mathrm{~B}$ beads, and PTE Sepharose $6 \mathrm{~B}$ beads. The results showed that FUS/TLS bound to the PTE Sepharose 6B beads, but not control Sepharose 6B beads (Figure 1(c)). EWS and TAF15, which belong to FET family as well, also bound to the PTE Sepharose beads (Figure 1(c)). However, TDP-43, SOD1, and $\beta$-actin were not associated with the PTE Sepharose 6B beads (Figure 1(c)), suggesting that FET family proteins interacted specifically with PTE. The same results were observed with MOLT-3 cells (Figure $1(\mathrm{~d})$ ). Therefore, these results indicate that PTE interacts with FET family proteins.

3.3. Degradation of FET Family Proteins by PTE. To further investigate the physiological importance of the interaction between PTE and FET family proteins, we examined whether PTE affected the expression of FET family proteins. Different concentrations of PTE were added to SK-N-SH cells, and the samples were incubated for $24 \mathrm{~h}$. The expression of FUS/TLS, EWS, TAF15 was significantly decreased after treatment with PTE (Figure 2(a)). In addition, the expression of FUS/TLS was reduced as early as $4 \mathrm{~h}$ after treatment with $200 \mu \mathrm{g} / \mathrm{mL}$ PTE, and this occurred in a time-dependent manner (Figure 2(b)). In contrast, no reduction in the expression of TDP-43 protein or SOD1 protein was observed in cells that had been treated with PTE (Figure 2(a)). Similar results were observed in the case of MOLT-3 cells that had been treated with PTE (data not shown). Although GTE or BTE also decreased the expression of FUS/TLS, PTE induced the greatest decrease of FUS/TLS protein expression (Figures 3(a) and 3(b)). PTE bound to FUS/TLS stronger than GTE (Figures 3(c) and 3(d)).

To investigate whether PTE is toxic to SK-N-SH cells, we treated cells with various concentrations of PTE for $24 \mathrm{~h}$ and cell viability assays were performed. No significant difference in the levels of cell viability among cells treated with different concentrations of PTE was found (Figure 4(a)). These results indicate that PTE is not toxic to SK-N-SH cells. We next determined whether PTE led to the transcriptional inhibition of FUS/TLS. Quantitative RT-PCR was performed to detect FUS/TLS mRNA expression levels in SK-N-SH cells treated with PTE or not treated. No significant difference was found, compared with the control (Figure 4(b)). Similar results were observed in MOLT-3 cells (data not shown).

3.4. Lysosome-Dependent Degradation of FUS/TLS by PTE. The lysosomal system and the ubiquitin-proteasome system are responsible for the majority of intracellular protein degradation. To investigate the mechanism of FUS/TLS degradation, we assessed the effects of proteasome and lysosome 


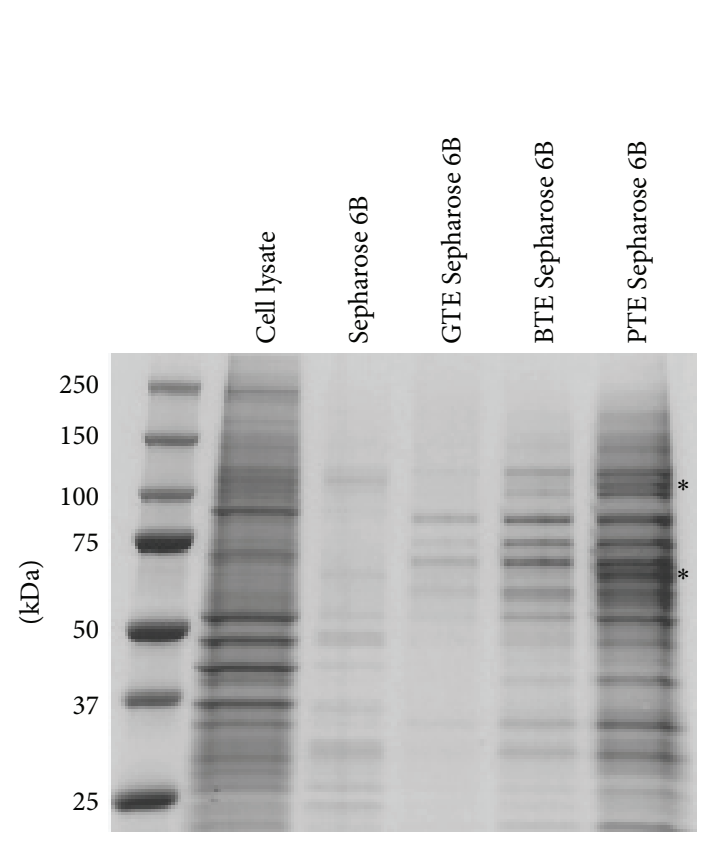

(a)

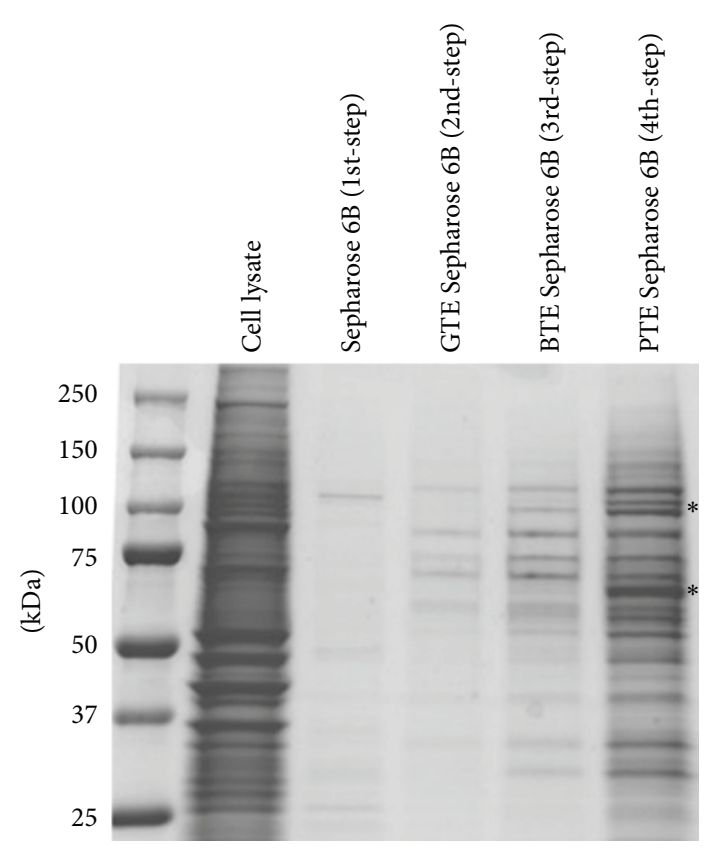

(b)

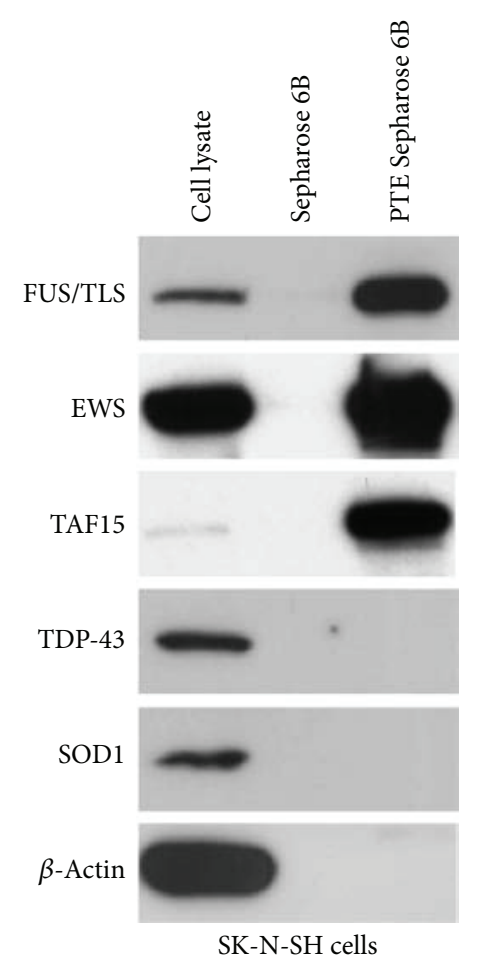

(c)

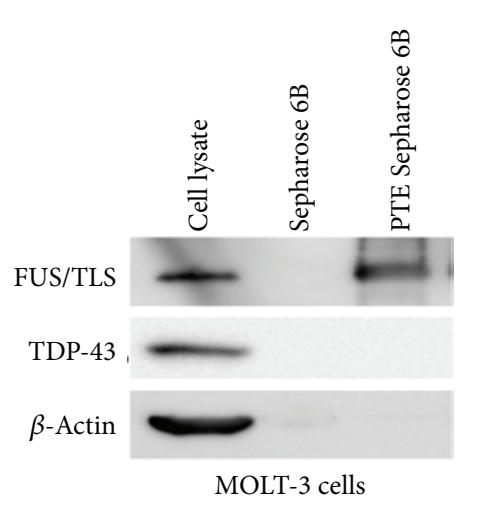

(d)

FIGURE 1: Purification and identification of the PTE associated protein. (a) Proteins derived from MOLT-3 cells were, respectively, loaded onto the four types of Sepharose 6B beads, and the proteins that were bound to the beads were analyzed on SDS-PAGE gels and stained with Coomassie brilliant blue. (b) A four-step purification procedure of PTE-associated proteins was performed. MOLT-3 cell lysates were sequentially loaded onto Sepharose 6B beads, GTE Sepharose 6B beads, and BTE Sepharose 6B beads, followed by PTE Sepharose 6B beads. The PTE-associated proteins were finally purified with PTE Sepharose $6 \mathrm{~B}$ beads. The proteins, as indicated by the arrow, were removed from the gel and analyzed using MALDI-TOF MS. (c) SK-N-SH cell lysates and (d) MOLT-3 cell lysates were incubated with PTE Sepharose 6B or Sepharose 6B beads and analyzed by Western blot. 


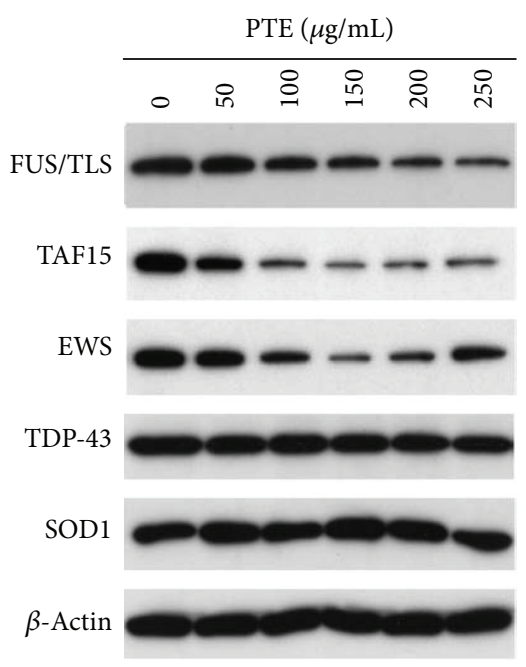

(a)

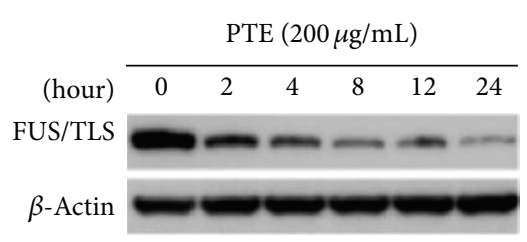

(b)
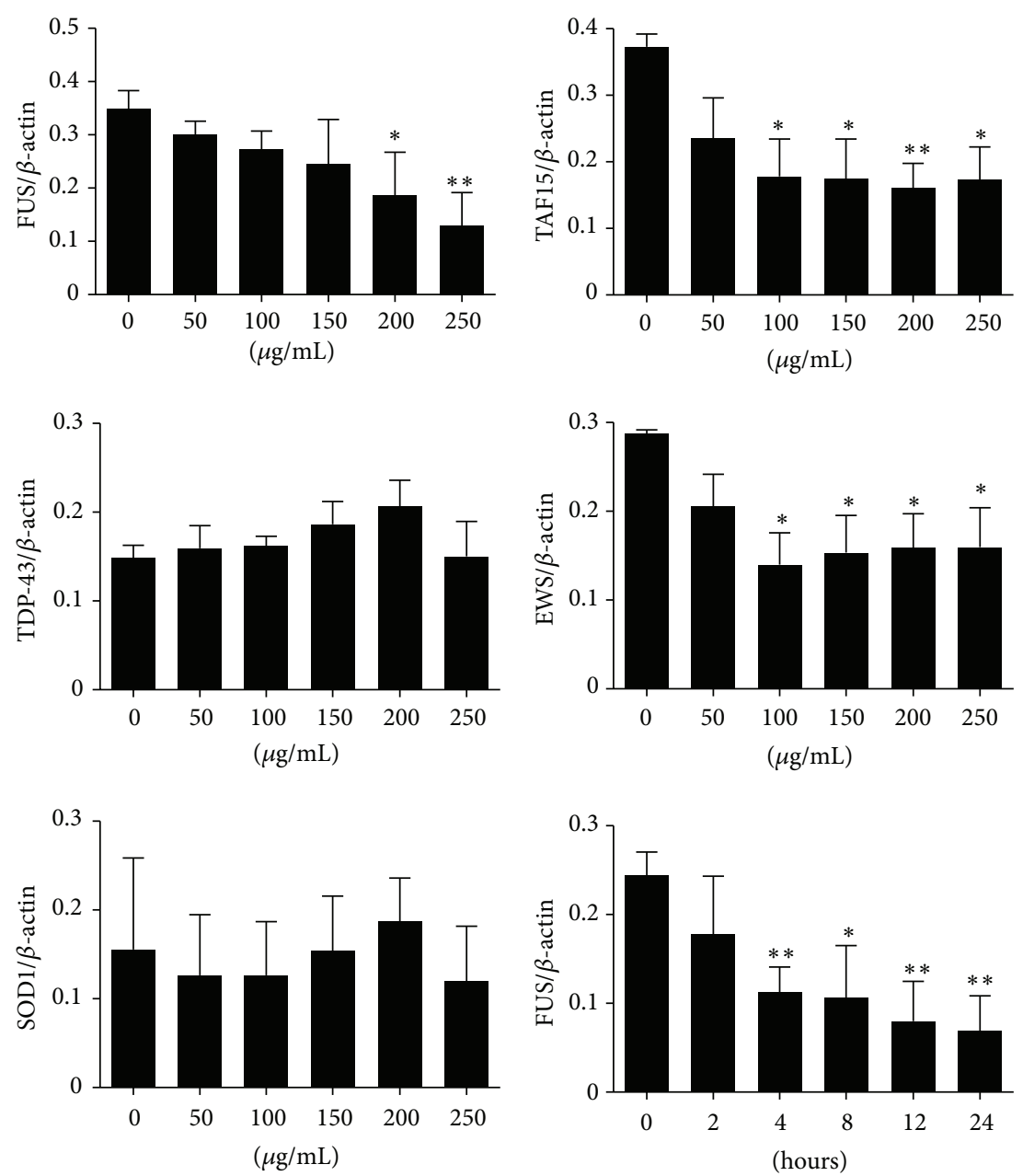

(c)

FIgURE 2: Decreased FET family protein expression by PTE in SK-N-SH cells. (a) Cells were treated with different concentrations of PTE for $24 \mathrm{~h}$; the expression of FUS/TLS, EWS, TAF15, TDP-43, SOD1, and $\beta$-actin was detected by Western blot. (b) Cells were treated with $200 \mu \mathrm{g} / \mathrm{mL}$ PTE for different time periods; Western blot was performed. (c) The Western blot results were quantified and statistical analysis was performed. Values are mean \pm SEM of three independent experiments. ${ }^{*} P<0.05$, ${ }^{* *} P<0.01$, and ${ }^{* * *} P<0.001$ compared with untreated control.

inhibitors on PTE-induced FUS/TLS degradation. SK-N-SH cells were pretreated with lysosome or proteasome inhibitors for $1 \mathrm{~h}$ prior to PTE addition. FUS/TLS expression levels were assessed by Western blot. Pretreatment with $\mathrm{NH}_{4} \mathrm{Cl}$ prevented the PTE-induced FUS/TLS protein degradation (Figure 5(a)). However, Lactacystin did not affect PTEinduced FUS/TLS protein degradation in SH-N-SH cells (Figure 5(b)). These results indicate that PTE induces FUS/TLS protein degradation via the lysosome-dependent pathway.

3.5. Degradation of the Mutant FUS/TLS Protein by PTE. We assessed whether PTE induces the degradation of mutant FUS/TLS proteins. The R521C FUS/TLS mutation is the most common form of mutation, and it is characterized by an early onset and rapid progress of ALS symptoms.
We transfected the R521C mutant gene into SK-N-SH cells and treated transfected cells with or without PTE. PTE induced the degradation of R521C FUS/TLS proteins. In contrast, PTE had no effect on the level of LDLR protein in transfected cells (Figure 6(a)). The evidence for an interaction between R521C FUS/TLS and PTE was demonstrated by a pull-down assay using Sepharose 6B beads and PTE Sepharose 6B beads (Figure 6(b)). In order to further investigate the effect of PTE on R521C FUS/TLS proteins, SK-N-SH cells that stably expressed R521C FUS/TLS were established. In the SK-N-SH cells stably expressing R521C FUS/TLS, R521C FUS/TLS proteins had increased cytoplasmic location (Figure 7(a)). PTE induced the degradation of R521C FUS/TLS proteins (Figure 5(a)) and decreased the expression of the cytoplasmic R521C FUS/TLS proteins (Figure 7(a)). 


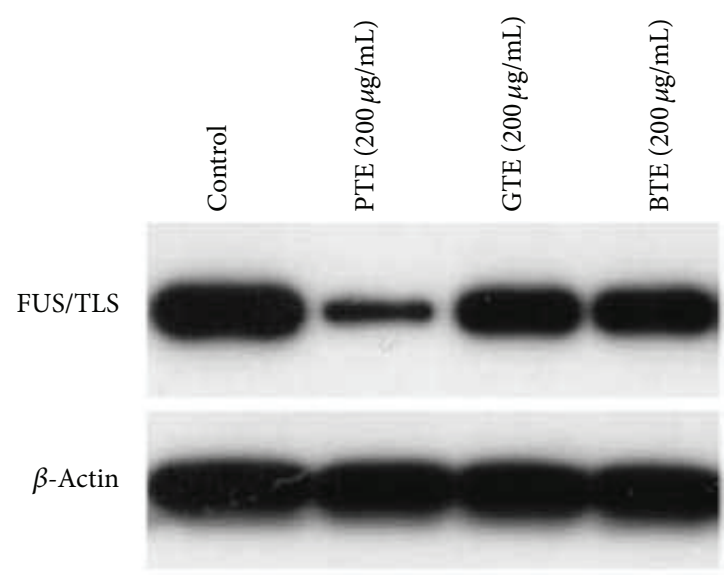

(a)

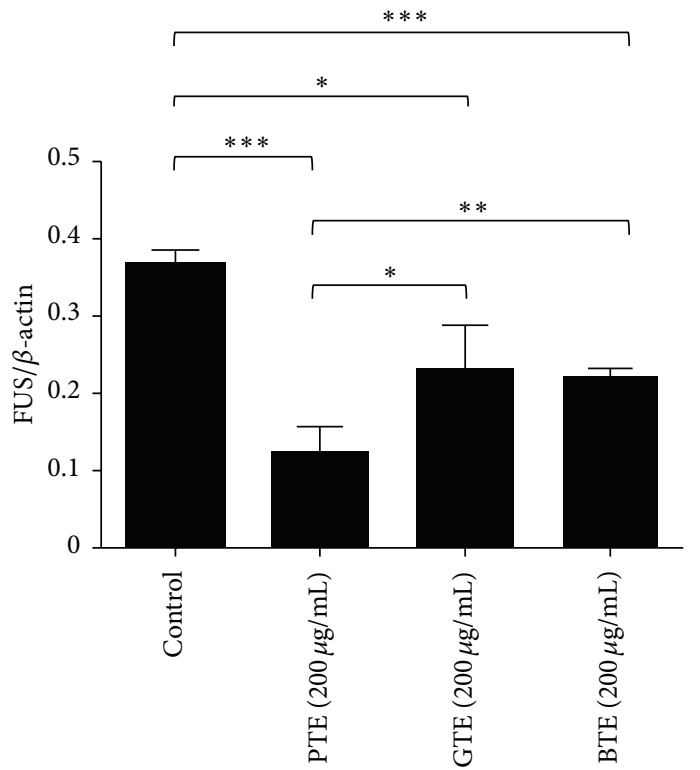

(b)

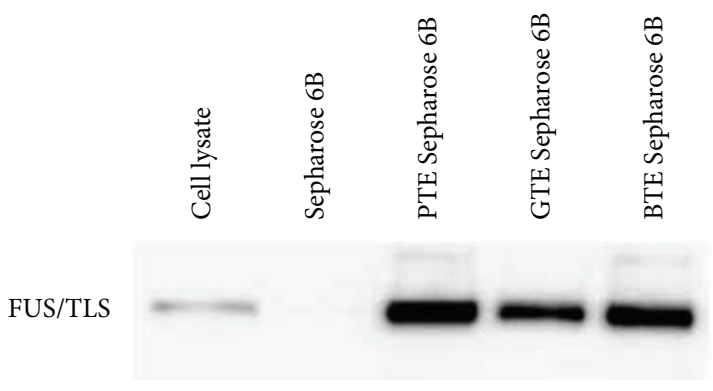

(c)

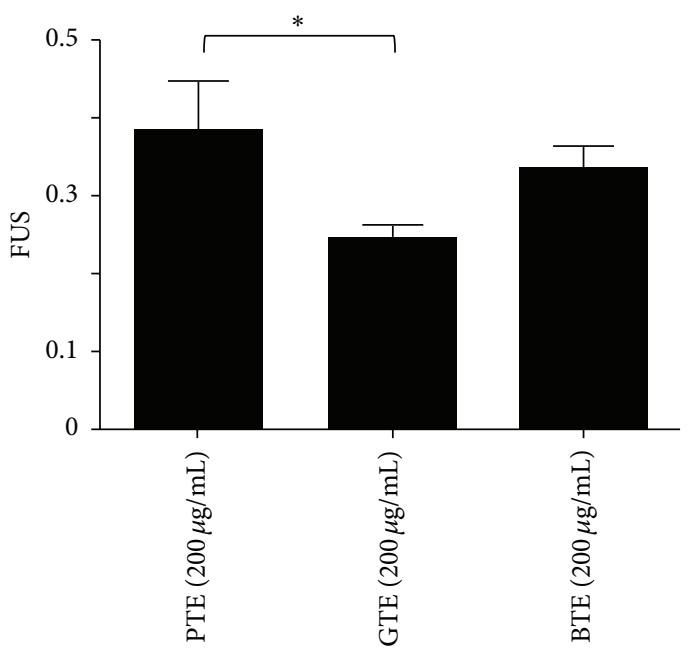

(d)

FIGURE 3: Effects of three different tea extracts on FUS/TLS in SK-N-SH cells. (a) Cells were treated with $200 \mu \mathrm{g} / \mathrm{mL}$ PTE, GTE, or BTE for $24 \mathrm{~h}$; the expression of FUS/TLS was detected by Western blot. (b) The Western blot results were quantified and statistical analysis was performed. Values are mean \pm SEM of three independent experiments. ${ }^{*} P<0.05,{ }^{* *} P<0.01$, and ${ }^{* * *} P<0.001$ compared with untreated control. (c) Cell lysates were incubated with PTE Sepharose 6B, GTE Sepharose 6B, BTE Sepharose 6B, or Sepharose 6B beads, and the levels of bound FUS/TLS were analyzed by Western blot. (d) The Western blot results were quantified and statistical analysis was performed. Values are mean \pm SEM of three independent experiments. ${ }^{*} P<0.05$.

3.6. Reduction of FUS-Positive Cytoplasmic Granules by PTE under Stress Conditions. FUS/TLS with ALS-causing mutations is incorporated into cytoplasmic stress granules under stress conditions and is important in the pathogenesis of ALS [24-27]. Sodium arsenite is commonly used to induce oxidative stress in in vitro models. To assess whether PTE affects the incorporation of mutant FUS/TLS into stress granules, we treated SK-N-SH cell lines stably expressing R521C FUS/TLS mutation (V5 tagged) with PTE $(200 \mu \mathrm{g} / \mathrm{mL})$ for $24 \mathrm{~h}$ and with $1 \mathrm{mM}$ sodium arsenite for 1 hour, which increases intracellular ROS [28] and induces stress granules formation [29]. Cells were immunostained with anti-V5 (red,
FUS) and DAPI (blue, nuclear marker) and observed under confocal microscopy. R521C FUS/TLS was incorporated into cytoplasmic stress granules under stress condition. PTE significantly reduced the number of FUS-positive cytoplasmic granules following sodium arsenite treatment (Figure 7(b)).

\section{Discussion}

The findings reported here show that PTE inhibits the expression of FET family proteins, but it has no effect on FUS/TLS mRNA levels in SK-N-SH cells, which suggests that 


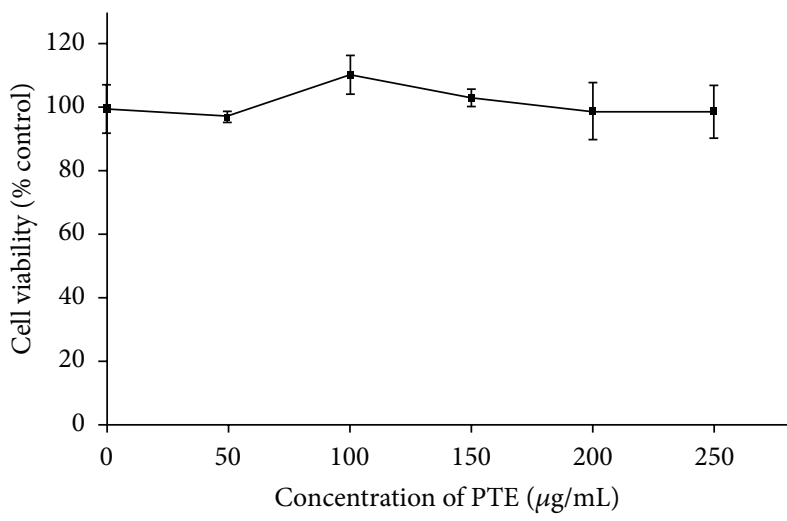

(a)

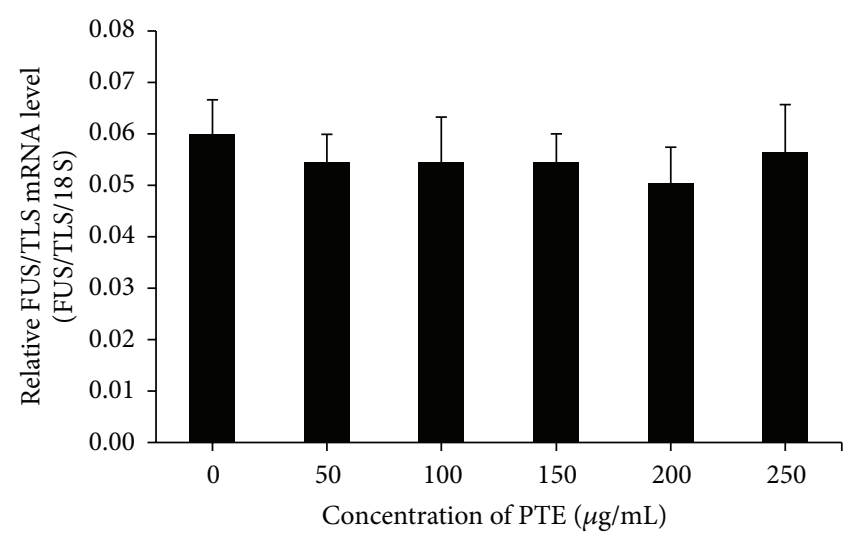

(b)

FIGURE 4: Effect of PTE on cell viability and FUS/TLS mRNA expression in SK-N-SH cells. Cells were treated with different concentrations of PTE for $24 \mathrm{~h}$. (a) Cell viability was measured by trypan blue staining. Percentage viability was defined as the number of viable cells in treated versus untreated cells. (b) FUS/TLS mRNA expression was analyzed by quantitative RT-PCR. Values are mean \pm SEM of three independent experiments. ${ }^{*} P<0.05,{ }^{* *} P<0.01$, and ${ }^{* * *} P<0.001$ compared with untreated control.

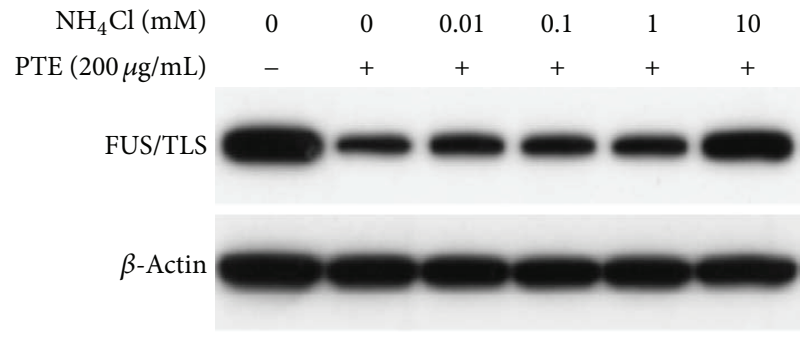

SK-N-SH cells

(a)

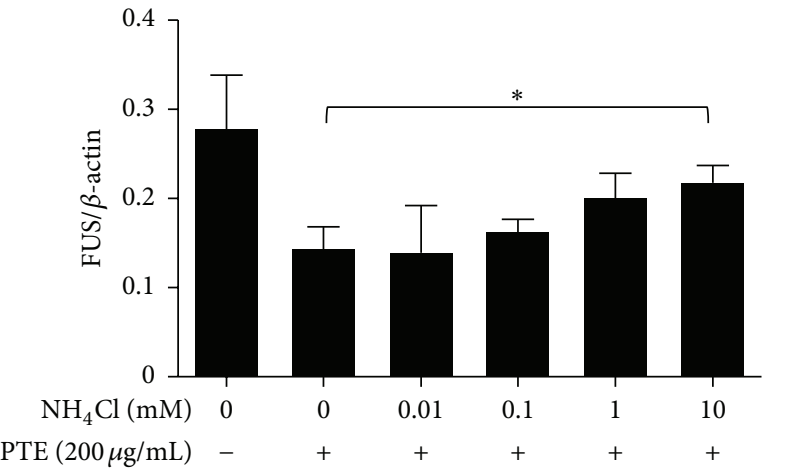

(c)

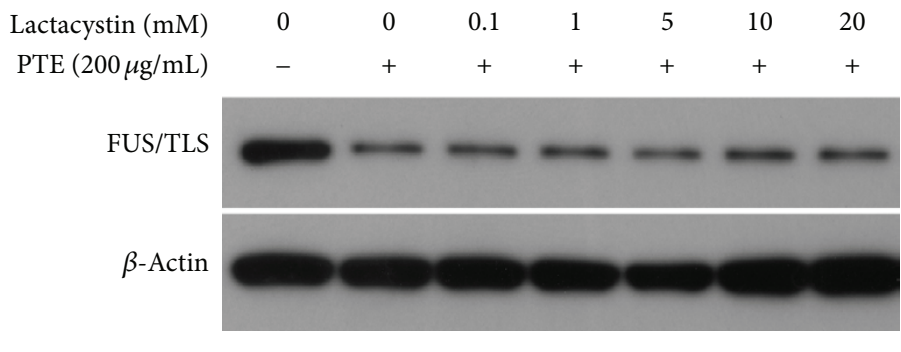

SK-N-SH cells

(b)

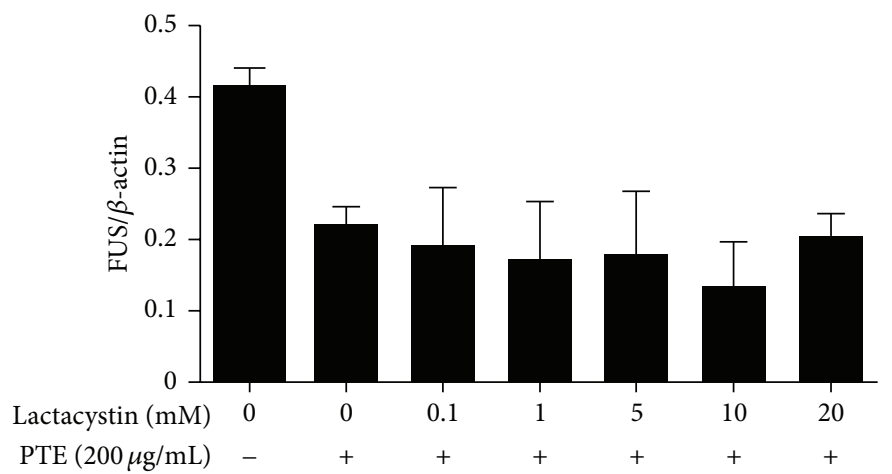

(d)

FIGURE 5: Lysosome-dependent degradation of FUS/TLS by PTE. SK-N-SH cells were incubated with or without inhibitor for $1 \mathrm{~h}$, (a) ammonium chloride $\left(\mathrm{NH}_{4} \mathrm{Cl}\right)$, a lysosome inhibitor, or (b) lactacystin, a proteasome inhibitor, followed by treatment with PTE $(200 \mu \mathrm{g} / \mathrm{mL})$ for $24 \mathrm{~h}$. Cell lysates were detected by Western blot with anti-FUS/TLS. $\beta$-actin was used as the loading control. (c) (d) The Western blot results were quantified and statistical analysis was performed. Values are mean \pm SEM of three independent experiments. ${ }^{*} P<0.05$, ${ }^{* *} P<0.01$, and ${ }^{* * *} P<0.001$ compared with treated with PTE only.

the inhibition occurs via a posttranscriptional mechanism. In addition, most of the cells survived after PTE treatment. This result indicates that the decrease in the level of FUS/TLS protein was not the result of cell death. Furthermore, the data clearly show that PTE interacts with FET family proteins. TDP-43 and SOD-1 failed to interact with PTE, and their expressions were not inhibited by PTE. PTE induced a decrease in FUS/TLS protein levels in SH-N-SH cells, which was rescued by a lysosome inhibitor. Importantly, PTE also induced the degradation of R521 FUS/TLS protein. These results imply that the interaction between PTE and FUS/TLS leads to the degradation of FUS/TLS and its mutant protein. 


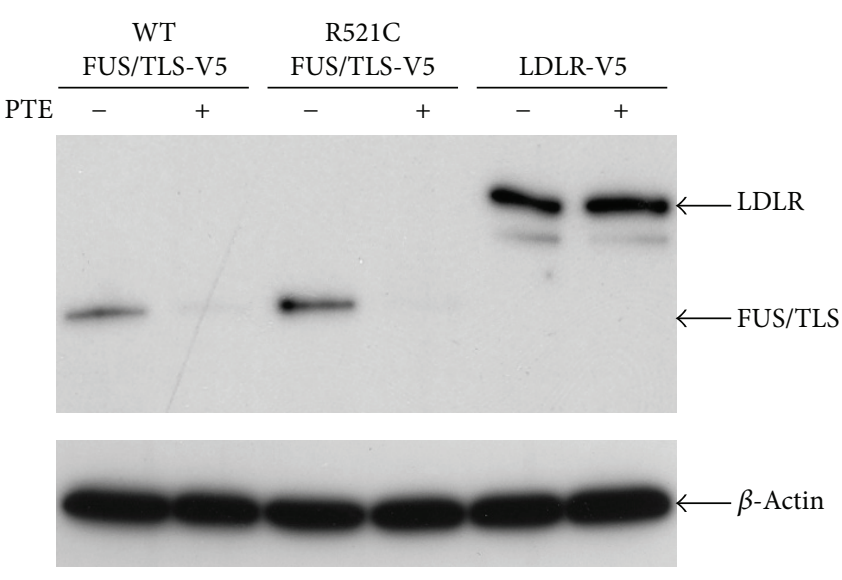

(a)

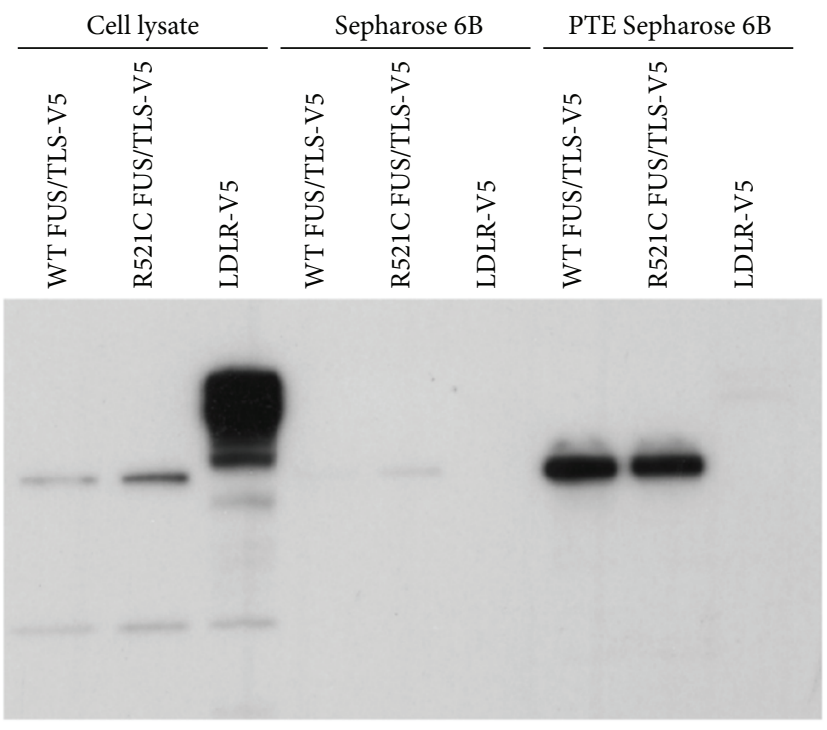

(b)

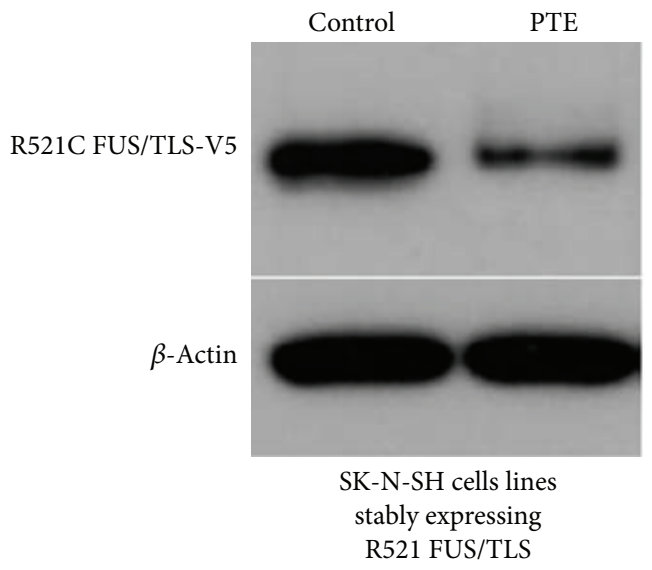

(c)

FIGURE 6: Degradation of R521C FUS/TLS protein by PTE. (a) SK-N-SH cells were transfected with V5-tagged wild-type FUS/TLS or R521C FUS/TLS or LDLR. Transfected cells were treated with or without PTE $(200 \mu \mathrm{g} / \mathrm{mL})$ for $24 \mathrm{~h}$. Cell lysates were detected by Western blot with anti-V5 antibody. (b) HEK 293T cells were transfected with V5-tagged wild-type FUS/TLS, R521C FUS/TLS, or LDLR. Protein extracts from transfected 293T cells were incubated with PTE Sepharose 6B or Sepharose 6B beads. Proteins that were bound to the beads were analyzed by Western blot with anti-V5 antibody. (c) SK-N-SH cells stably expressing R521C FUS/TLS were treated with or without PTE (200 $\mu \mathrm{g} / \mathrm{mL}$ ) for $24 \mathrm{~h}$. Cell lysates were detected by Western blot with anti-V5 antibody. $\beta$-actin was used as the loading control.

Tea is one of the most popular and widely consumed beverages in the world. Unlike green tea, pu-erh tea contains a number of compounds that are produced as the result of the preparation process. Human epidemiological and animal research experiments suggest that the pharmacological benefits of tea drinking may help protect the brain as we age. There is a growing body of evidence to indicate that polyphenol compounds have the ability to convert large, mature $\alpha$-synuclein, and amyloid- $\beta$ fibrils into smaller, amorphous protein aggregates that are nontoxic to mammalian cells [30-32]. Epigallocatechin gallate (EGCG) significantly reduces the aggregation and cytotoxicity of the Huntington protein containing polyglutamine (polyQ) in a yeast model of Huntington's disease [33]. It should also be noted that tea drinking has been shown to exert neuroprotective activities in a wide array of cellular and animal models of neurological disorders [34]. In this study, we prepared three different tea extracts Sepharose beads to screen the proteins strongly associated with PTE. FUS/TLS was identified as a PTEassociated protein. Although FUS/TLS also could bind to GTE and BTE, PTE did have the greatest capacity to bind to FUS/TLS among those three different tea extracts. Perhaps this may account for the apparent absence of FUS/TLS in the proteins that bind to GTE or BTE Sepharose $6 \mathrm{~B}$ beads in Coomassie brilliant staining. EGCG is the most abundant catechin in tea. EGCG is found mainly in green tea 


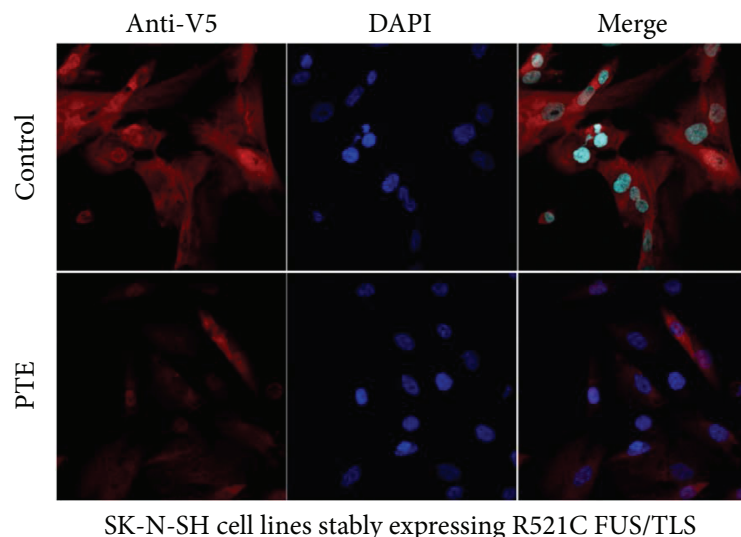

(a)

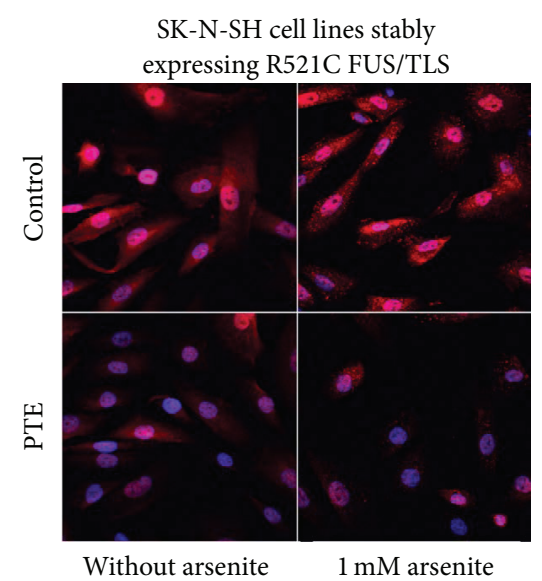

(b)

FIGURE 7: Reduction in FUS-positive cytoplasmic granules by PTE under stress conditions. (a) SK-N-SH cells stably expressing R521C FUS/TLS were treated with or without PTE $(200 \mu \mathrm{g} / \mathrm{mL})$ for $24 \mathrm{~h}$. (b) SK-N-SH cells stably expressing R521C FUS/TLS were treated with or without PTE $(200 \mu \mathrm{g} / \mathrm{mL})$ for $24 \mathrm{~h}$, following treatment with $1 \mathrm{mM}$ arsenite. Cells were subsequently fixed and analyzed by immunofluorescence microscopy using anti-V5 antibody and DAPI.

but, in smaller quantities, in black tea and Pu-erh Tea. We were not able to observe the degradation of FUS/TLS after treatment with EGCG (data not shown).

Protein aggregation in neurons is associated with a number of neurodegenerative disorders. Exactly how FET and TDP-43, either the mutant or wild-type form, contribute to these diseases remains unclear. Two main potential mechanisms have been proposed. First, since FET and TDP-43 are both RNA-binding proteins, these proteins are normally located in the nucleus and are involved in RNA processing. Therefore, the aggregation of proteins in the cytoplasm inhibits their physiological function. Second, the cytoplasmic aggregations formed from these proteins are toxic to cells. ALS-linked FUS mutations are mostly localized to the cytoplasm. Following stress, FUS/TLS is incorporated into stress granules, thereby initiating the aggregation and sequestration of wild-type FUS/TLS [35]. We have also shown that cytoplasmic R521C FUS is incorporated into stress granules following cellular stress in SK-N-SH cell lines stably expressing R521C FUS/TLS. The results of the current study raise questions concerning the physiological significance of the FET family proteins degradation induced by PTE. PTE may prevent protein aggregation and enable cells to function normally with normal levels of FET family proteins. There are currently no FET family protein-targeted therapies available for the treatment of ALS. The decreased levels of a toxic FET family proteins or mutant FET family proteins might be efficacious for FET family protein-associated ALS. Further studies are required to assess whether the PTE-induced reduction in FET family proteins is also observed in in vivo FET family proteins proteinopathies models.

\section{Conclusion}

The findings of this study revealed that PTE interacted with FET family proteins but not with TDP-43 or SOD1 protein. PTE induced the degradation of FET family proteins but had no effect on TDP-43 or SOD1. Additionally, PTE induced the degradation of R521C FUS/TLS protein. PTE significantly decreased the expression of cytoplasmic R521C FUS/TLS protein and the number of FUS-positive cytoplasmic granules under stress conditions. These findings contribute to our understanding of the molecular mechanism underlying the antineurodegenerative effects of PTE and suggest that pu-erh tea maybe helpful in preventing the onset of FET family protein-associated neurodegenerative diseases and in delaying the progression of these types of diseases through inhibiting the cytoplasmic aggregation of FET family proteins.

\section{Conflict of Interests}

The authors declare that there is no conflict of interests regarding the publication of this paper.

\section{Acknowledgments}

The authors would like to thank Dr. Noriko Fujiwara for providing anti-SOD1 antibody and helpful discussions. They also would like to thank Nana Iwami for technical assistance. This research was supported by the Pu-erh Tea Research Institute (Yunnan, China).

\section{References}

[1] J. Mitchell and G. Borasio, "Amyotrophic lateral sclerosis," The Lancet, vol. 369, no. 9578, pp. 2031-2041, 2007.

[2] D. R. Rosen, T. Siddique, D. Patterson et al., "Mutations in $\mathrm{Cu} / \mathrm{Zn}$ superoxide dismutase gene are associated with familial amyotrophic lateral sclerosis," Nature, vol. 362, no. 6415, pp. 5962, 1993. 
[3] M. Neumann, D. M. Sampathu, L. K. Kwong et al., "Ubiquitinated TDP-43 in frontotemporal lobar degeneration and amyotrophic lateral sclerosis," Science, vol. 314, no. 5796, pp. 130-133, 2006.

[4] J. Sreedharan, I. P. Blair, V. B. Tripathi et al., "TDP-43 mutations in familial and sporadic amyotrophic lateral sclerosis," Science, vol. 319, no. 5870, pp. 1668-1672, 2008.

[5] E. Kabashi, P. N. Valdmanis, P. Dion et al., "TARDBP mutations in individuals with sporadic and familial amyotrophic lateral sclerosis," Nature Genetics, vol. 40, no. 5, pp. 572-574, 2008.

[6] T. J. Kwiatkowski Jr., D. A. Bosco, A. L. LeClerc et al., "Mutations in the FUS/TLS gene on chromosome 16 cause familial amyotrophic lateral sclerosis," Science, vol. 323, no. 5918, pp. 12051208, 2009.

[7] C. Vance, B. Rogelj, T. Hortobágyi et al., "Mutations in FUS, an RNA processing protein, cause familial amyotrophic lateral sclerosis type 6," Science, vol. 323, no. 5918, pp. 1208-1211, 2009.

[8] J. Couthouisa, M. P. Harta, J. Shorter et al., "A yeast functional screen predicts new candidate ALS disease genes," Proceedings of the National Academy of Sciences of the United States of America, vol. 108, no. 52, pp. 20881-20890, 2011.

[9] J. Couthouis, M. P. Hart, R. Erion et al., "Evaluating the role of the FUS/TLS-related gene EWSR1 in amyotrophic lateral sclerosis," Human Molecular Genetics, vol. 21, no. 13, pp. 28992911, 2012.

[10] J. R. Tollervey, T. Curk, B. Rogelj et al., "Characterizing the RNA targets and position-dependent splicing regulation by TDP-43," Nature Neuroscience, vol. 14, no. 4, pp. 452-458, 2011.

[11] M. Polymenidou, C. Lagier-Tourenne, K. R. Hutt et al., "Long pre-mRNA depletion and RNA missplicing contribute to neuronal vulnerability from loss of TDP-43," Nature Neuroscience, vol. 14, no. 4, pp. 459-468, 2011.

[12] C. Lagier-Tourenne, M. Polymenidou, and D. W. Cleveland, "TDP-43 and FUS/TLS: emerging roles in RNA processing and neurodegeneration," Human Molecular Genetics, vol. 19, no. 1, Article ID ddq137, pp. R46-R64, 2010.

[13] I. R. A. Mackenzie, O. Ansorge, M. Strong et al., "Pathological heterogeneity in amyotrophic lateral sclerosis with FUS mutations: two distinct patterns correlating with disease severity and mutation," Acta Neuropathologica, vol. 122, no. 1, pp. 87-98, 2011.

[14] N. Suzuki, M. Aoki, H. Warita et al., "FALS with FUS mutation in Japan, with early onset, rapid progress and basophilic inclusion," Journal of Human Genetics, vol. 55, no. 4, pp. 252254,2010

[15] S. Watanabe, K. Kaneko, and K. Yamanaka, "Accelerated disease onset with stabilized familial amyotrophic lateral sclerosis (ALS)-linked mutant TDP-43 proteins," The Journal of Biological Chemistry, vol. 288, no. 5, pp. 364-354, 2013.

[16] N. Egawa, S. Kitaoka, K. Tsukita et al., "Drug screening for ALS using patient-specific induced pluripotent stem cells," Science Translational Medicine, vol. 4, no. 145, 2012.

[17] J. C. Mitchell, P. McGoldrick, C. Vance et al., "Overexpression of human wild-type FUS causes progressive motor neuron degeneration in an age- and dose-dependent fashion," Acta Neuropathologica, vol. 125, no. 2, pp. 273-288, 2013.

[18] C. Huang, H. Zhou, J. Tong et al., "FUS transgenic rats develop the phenotypes of amyotrophic lateral sclerosis and frontotemporal lobar degeneration," PLoS Genetics, vol. 7, no. 3, Article ID e1002011, 2011.
[19] A. Rietveld and S. Wiseman, "Antioxidant effects of tea: evidence from human clinical trials," Journal of Nutrition, vol. 133, no. 10, pp. 3285S-3292S, 2003.

[20] K.-C. Jeng, C.-S. Chen, Y.-P. Fang, R. C.-W. Hou, and Y.-S. Chen, "Effect of microbial fermentation on content of statin, GABA, and polyphenols in Pu-erh tea," Journal of Agricultural and Food Chemistry, vol. 55, no. 21, pp. 8787-8792, 2007.

[21] H. Zhao, M. Zhang, L. Zhao, Y.-K. Ge, J. Sheng, and W. Shi, "Changes of constituents and activity to apoptosis and cell cycle during fermentation of tea," International Journal of Molecular Sciences, vol. 12, no. 3, pp. 1862-1875, 2011.

[22] S.-J. Yan, L. Wang, Z. Li et al., "Inhibition of advanced glycation end product formation by $\mathrm{Pu}$-erh Tea ameliorates progression of experimental diabetic nephropathy," Journal of Agricultural and Food Chemistry, vol. 60, no. 16, pp. 4102-4110, 2012.

[23] L. X. Luo, X. C. Wu, Y. L. Deng, and S. W. Fu, "Variations of main biochemical components and their relations to quality formation during pile-fermentation process of Yunnan puerh tea," Journal of Tea Science, vol. 18, pp. 53-60, 1998.

[24] D. A. Bosco, N. Lemay, H. K. Ko et al., "Mutant FUS proteins that cause amyotrophic lateral sclerosis incorporate into stress granules," Human Molecular Genetics, vol. 19, no. 21, Article ID ddq335, pp. 4160-4175, 2010.

[25] D. Dormann, R. Rodde, D. Edbauer et al., "ALS-associated fused in sarcoma (FUS) mutations disrupt transportin-mediated nuclear import," EMBO Journal, vol. 29, no. 16, pp. 2841-2857, 2010.

[26] J. Gal, J. Zhang, D. M. Kwinter et al., "Nuclear localization sequence of FUS and induction of stress granules by ALS mutants," Neurobiology of Aging, vol. 32, no. 12, pp. 2323-e27, 2011.

[27] C. Vance, E. L. Scotter, A. L. Nishimura et al., "ALS mutant FUS disrupts nuclear localization and sequesters wild-type FUS within cytoplasmic stress granules," Human Molecular Genetics, vol. 22, no. 13, pp. 2676-2688, 2013.

[28] C.-K. Lii, A.-H. Lin, S.-L. Lee, H.-W. Chen, and T.-S. Wang, "Oxidative modifications of proteins by sodium arsenite in human umbilical vein endothelial cells," Environmental Toxicology, vol. 26, no. 5, pp. 459-471, 2011.

[29] M. G. Thomas, L. J. M. Tosar, M. A. Desbats, C. C. Leishman, and G. L. Boccaccio, "Mammalian Staufen 1 is recruited to stress granules and impairs their assembly," Journal of Cell Science, vol. 122, no. 4, pp. 563-573, 2009.

[30] J. Bieschke, J. Russ, R. P. Friedrich et al., "EGCG remodels mature $\alpha$-synuclein and amyloid- $\beta$ fibrils and reduces cellular toxicity," Proceedings of the National Academy of Sciences of the United States of America, vol. 107, no. 17, pp. 7710-7715, 2010.

[31] F. Meng, A. Abedini, A. Plesner, C. B. Verchere, and D. P. Raleigh, "The Flavanol (-)-epigallocatechin 3-gallate inhibits amyloid formation by islet amyloid polypeptide, disaggregates amyloid fibrils, and protects cultured cells against IAPPinduced toxicity," Biochemistry, vol. 49, no. 37, pp. 8127-8133, 2010.

[32] G. Grelle, A. Otto, M. Lorenz, R. F. Frank, E. E. Wanker, and J. Bieschke, "Black tea theaflavins inhibit formation of toxic amyloid- $\beta$ and $\alpha$-synuclein fibrils," Biochemistry, vol. 50, no. 49, pp. 10624-10636, 2011.

[33] D. E. Ehrnhoefer, M. Duennwald, P. Markovic et al., "Green tea (-)-epigallocatechin-gallate modulates early events in huntingtin misfolding and reduces toxicity in Huntington's disease 
models," Human Molecular Genetics, vol. 15, no. 18, pp. 27432751, 2006.

[34] S. A. Mandel, T. Amit, L. Kalfon, L. Reznichenko, and M. B. H. Youdim, "Targeting multiple neurodegenerative diseases etiologies with multimodal-acting green tea catechins," Journal of Nutrition, vol. 138, no. 8, pp. 1578S-1583S, 2008.

[35] C. Vance, E. L. Scotter, A. L. Nishimura et al., "ALS mutant FUS disrupts nuclear localization and sequesters wild-type FUS within cytoplasmic stress granules," Human Molecular Genetics, vol. 22, no. 13, pp. 2676-2688, 2013. 

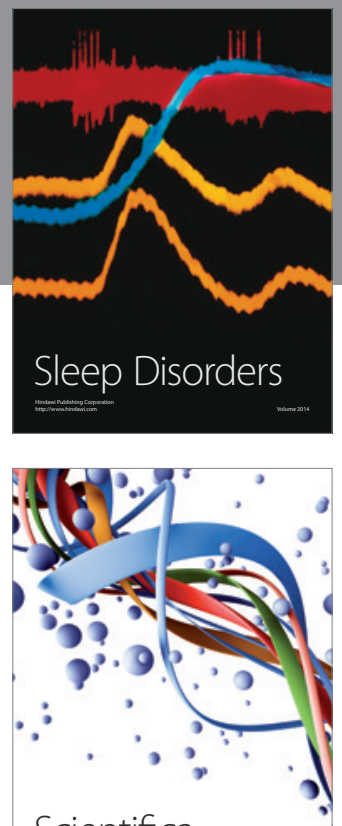

Scientifica
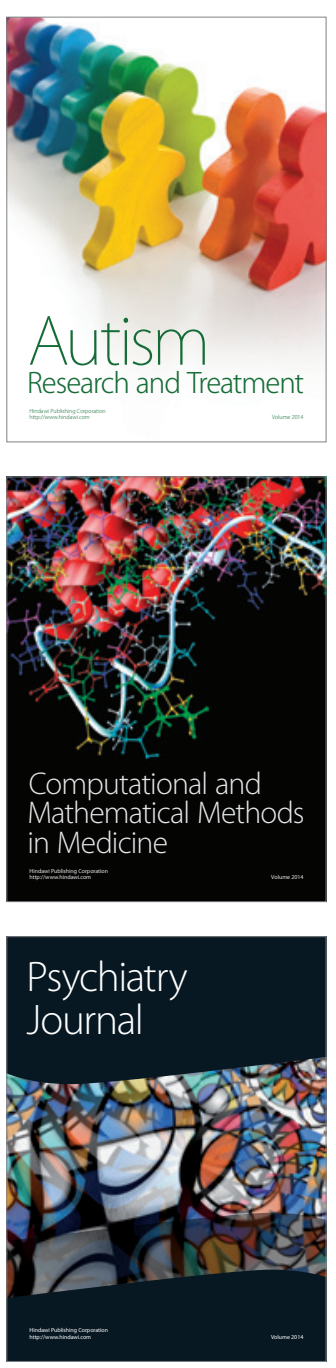
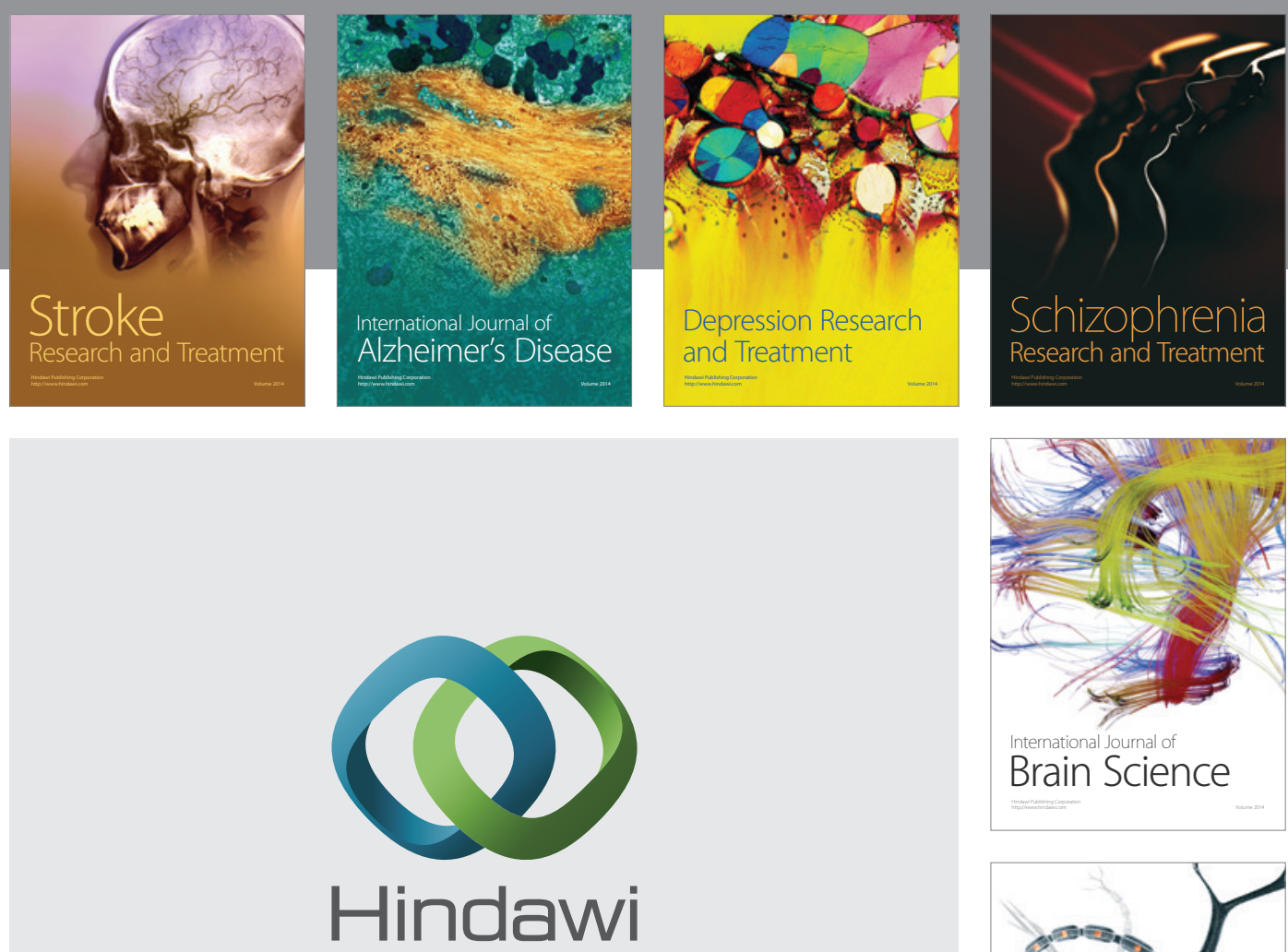

Submit your manuscripts at

http://www.hindawi.com
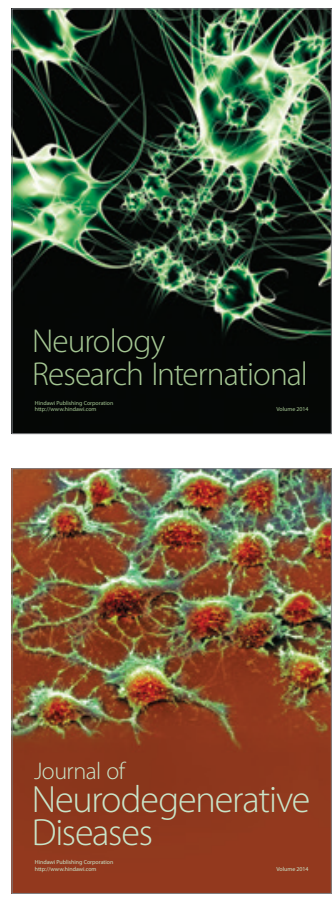

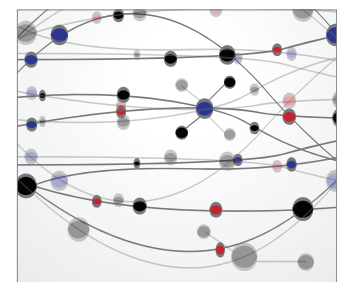

The Scientific World Journal
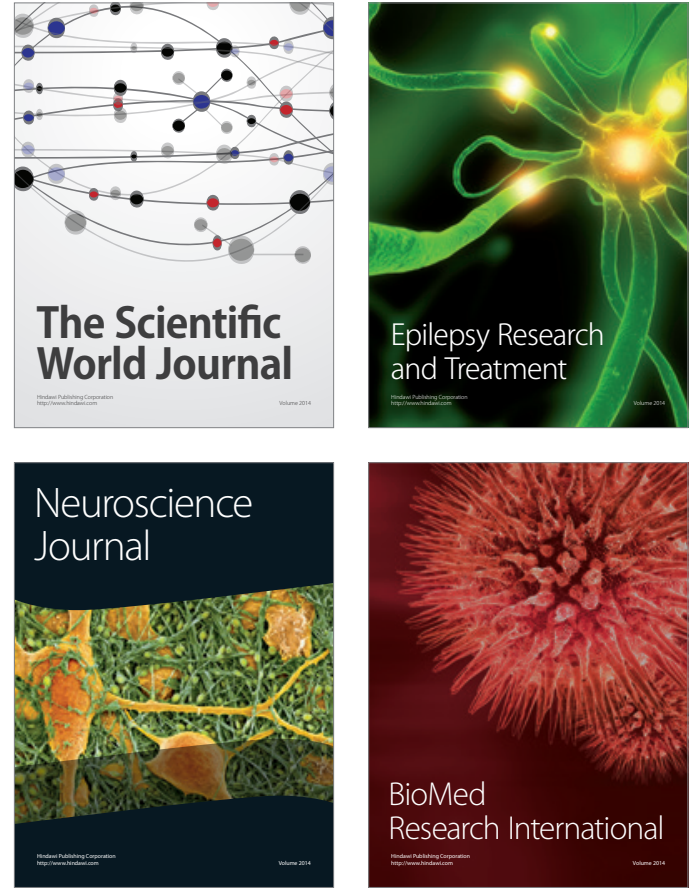

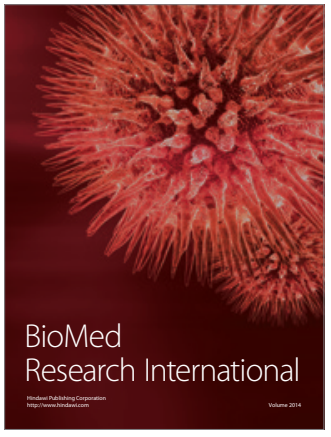

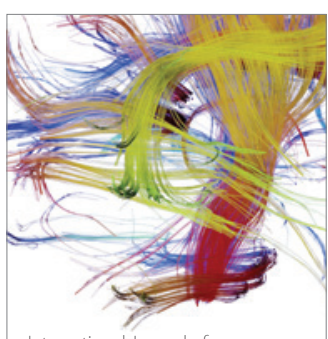

Brain Science

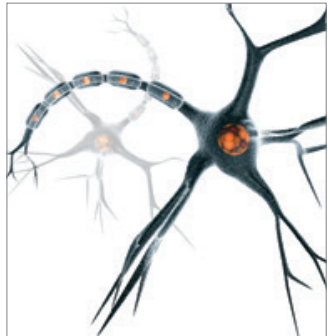

Neural Plasticity
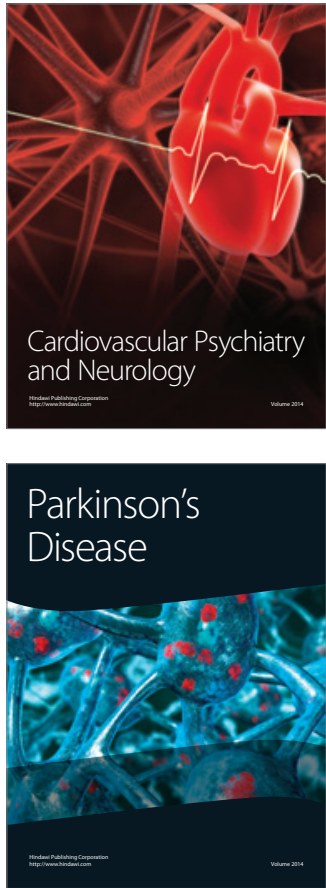